Journal of Beliefs and Values

https://www.tandfonline.com/loi/cjbv20

https://doi.org/10.1080/13617672.2020.1805925

\title{
An Investigation into Secondary Teachers' Views of Argumentation in Science and Religious Education
}

\author{
Liam Guilfoyle $^{\mathrm{a} *}$, S. Erduran ${ }^{\mathrm{a}, \mathrm{b}}$ and W. Park ${ }^{\mathrm{a}}$
}

${ }^{a}$ Department of Education, University of Oxford, Oxford, Oxfordshire, England; ${ }^{b}$ The Norwegian Centre for Science Education, University of Oslo, Oslo, Norway.

*15 Norham Gardens, Oxford, OX2 6PY; liam.guilfoyle@education.ox.ac.uk

Bibliographic Notes:

Liam Guilfoyle is a postdoctoral research officer on the Oxford Argumentation in Religion and Science (OARS) project (www.oarseducation.com) at the Department of Education, University of Oxford, and a Research Member of Common Room at Kellogg College. (ORCID:

https://orcid.org/0000-0002-3736-0339)

Sibel Erduran is Professor of Science Education and Director of Research at the Department of Education, University of Oxford, Fellow of St. Cross College, and visiting professor at The Norwegian Centre for Science Education, University of Oslo. She is Editor-in-Chief of Science \& Education, Editor of International Journal of Science Education, and President of the European Science Education Research Association. Prof. Erduran is the Principal Investigator of the OARS Project. (ORCID: https://orcid.org/0000-0001-5226-0136)

Wonyong Park is a DPhil Candidate at the Department of Education and St. Anthony's College, University of Oxford. He is a research assistant on the OARS Project. (ORCID:

https://orcid.org/0000-0002-8911-5968)

This work was supported by the Templeton World Charity Foundation under Grant [TWCF0238]. 


\section{An Investigation into Secondary Teachers' Views of Argumentation in Science and Religious Education}

Citizens often face problems and dilemmas about which they need to make decisions and choices that impact their everyday lives. Some of these issues are related to science and religion. For example, genetic cloning, nuclear energy and climate change can potentially appeal to moral and religious values as well as scientific knowledge. The ability to coordinate knowledge and values in reaching justified conclusions has thus become increasingly important in contemporary democratic societies. The process of justification of knowledge claims with evidence and reasons is often referred to as 'argumentation'. Curriculum standards of school subjects such as science and religious education (RE) include references to argumentation, and teachers are expected to teach to these standards. Yet, there is often limited opportunity for teachers of conventionally disparate subjects to express their understanding of how argumentation is broadly conceptualised in their own subject and in relation to other school subjects. The primary purpose of this paper is to report an empirical study that investigated how science and RE teachers view the nature of argumentation. The empirical data were drawn from 16 science and $17 \mathrm{RE}$ teachers' responses to survey questions. The findings illustrate how teachers describe both the distinguishing features (e.g. the forms of evidence acceptable for substantiating a claim) and similarities (e.g. the structures and processes of argument construction) of argumentation in science and religious education.

Keywords: argumentation; teacher beliefs; science and religion

\section{Introduction}

Citizens often face problems and dilemmas about which they need to make decisions that impact their lives (Zeidler \& Nichols 2009). Some of these issues are related to the interplay of science and religion. For example, many end-of-life decisions rely on not only knowledge about human anatomy but also religious and moral values about life. Teachers are often situated in a pedagogical context where they need to address queries from students about such difficult dilemmas (Reiss 2008). Numerous international curriculum standards (e.g. Next Generation Science Standards in the USA) advocate the fostering of students' 
understandings and skills in order to participate in public debate and make informed decisions about scientific, socio-scientific and ethical issues that influence their lives (NGSS Lead States 2013). Students' acquisition of argumentation skills has thus emerged as a significant educational goal. Argumentation underpins debates and it also plays a central role in the building of explanations, models and theories (Siegel 1991). An argument is broadly defined in terms of the use of evidence to justify claims with warrants and backings (Toulmin, 1958). Argumentation as the process of constructing and evaluating arguments is a significant tool instrumental in the growth of knowledge (Kitcher 1988) as well as a vital component of disciplinary discourse (Pera 1994).

Argumentation can also be considered as an example of epistemic practices of a discipline where knowledge claims are substantiated with evidence and reasons in the context of that discipline (Duschl \& Osborne 2002). For example, the size and shape of finches can be used as sources of empirical evidence to justify claims about the adaptation of species to their natural habitat. Contemporary science education curriculum standards make explicit reference to the significance of empirical evidence in science. For instance, NSTA advocates that student understand 'Science is based on empirical evidence' (NSTA, 2019). In the case of other school subjects such as religious studies, the conceptualisation of arguments may emphasise the use of opinions and reasons. For example, the Religious Education Curriculum in Northern Ireland specifies that students' progression in their thinking, problem-solving and decision-making skills should involve 'giving reasons/opinions, to explaining reasons/opinions to addressing counter-arguments' (Council for the Curriculum Examinations and Assessment, 2009).

Although curriculum standards of school subjects such as science and religious studies include references to argumentation, and teachers are expected to teach to these standards, there is often limited opportunity for teachers of conventionally disparate 
subjects to express their understanding of how argumentation is broadly conceptualised in school subjects (e.g. Hall \& McKinney, 2014). For example, although there is some research on how science teachers perceive argumentation (e.g. Sadler, 2006), there is limited understanding of what teachers of one subject might perceive as the content of the other subject and how cross-curricular coherence can be established (Niemela \& Tirri, 2018). For instance, what do science teachers consider the nature of arguments in religious studies to be? How do religious education (RE) teachers treat scientific knowledge and scientific arguments in their lessons? What are the similarities and differences between arguments in science and religion, and what do they imply for teaching?

Such questions are central to understanding how argumentation can be effectively taught across cross-curricular goals and content such that students are equipped with the appropriate skills to differentiate arguments and to recognise their disciplinary nuances, with the ultimate goal of informed citizenship. It should be noted that although the interface of science and religion has been extensively studied in the educational research literature, for example in the context of evolution versus creationism debate (e.g. Basel et al., 2014), the particular focus on argumentation in the context of science and religious education is virtually inexistent (e.g. Erduran et al., 2019).

The primary purpose of this paper is thus to investigate how science and RE teachers view the nature of argumentation in science and religion. Argumentation in this sense is not about the generic science-religion debate (e.g. Stenmark, 2004) nor is it about the potential conflict between science and religion (e.g. Thagard \& Findlay, 2010). Rather, it is about the particular pedagogical instance of how teachers make sense of a reasoning pattern in their own subject versus another subject in the context of schooling. If particular variations might emerge between science and religious education teachers' characterisation and use of argumentation in their subjects, then such variations are of interest from an 
educational point of view given students will be exposed to them and will need to make sense of any similarities and differences. Hence, following a review of the literature on argumentation in school science and RE, an empirical study will be presented to illustrate the outcomes of research conducted with teachers in England. A primary aim of the funded project was to investigate how science and RE teachers make sense of argumentation.

\section{Literature Review}

In the context of science education, argumentation is identified as an area of research that has gained significant attention in recent years (Lee et al. 2009). This attention by researchers to argumentation studies was also visible in the recent review by Lin et al. (2014) showing that most of the top 10 highly cited papers in science education between 1998-2002 were concerned with the topic of argumentation. The review also illustrated that a handful of the top 10 highly cited papers in 2003-2007 were concerned with argumentation, including those with a focus on informal reasoning (Lin et al. 2014). These review data support the claim that the argumentation is a significant topic of investigation and has received enduring attention from science educators for over a decade (Lee et al. 2009; Lin et al. 2014). There are now also book length accounts of argumentation in science education research (Erduran \& Kaya, 2019; Erduran \& Jiménez-Aleixandre, 2007). Although similar data on research trends on argumentation in religious education is not available at this time, particular studies point to the importance of argumentation in the context of religious education as well. For example, Gottlieb (2001) investigated argumentation in Jewish education. Argumentation has been a key aspect of debates around the contrast of science and religion. For instance, the long-standing debate on creation versus evolution itself possesses an acknowledgment of argumentation as an inherent feature of such debates (Weiß 2016). 
Despite the increasing interest in argumentation in science education research, the precise nature of the trends in its coverage has not been previously documented in detail. Lin and colleagues (2014) indicated that in the past 15 years, argumentation has been studied mostly in the context of various socio-scientific issues. Similarly, within science education, the notions of 'epistemic practices', 'discourse' and 'socio-scientific issues' have been intricately linked to argumentation studies (Erduran \& Garcia-Mila, 2015; Sadler \& Zeidler 2005). From a science education research perspective, argumentation studies have not focused on RE as a topic of investigation until fairly recently (Erduran et al., 2019).

There are at least three disciplinary bodies of research framing argumentation studies in science education: (a) developmental psychology, highlighting argumentation as a form of formal language contributing to the development of cognitive capabilities; (b) language sciences, for instance the theory of communicative action; and (c) science studies, as in the interdisciplinary investigations on science drawing from history, philosophy and sociology of science (Erduran \& Jiménez-Aleixandre, 2007). By contrast, RE debates on foundational references in RE have ranged from theology to pluralistic RE (Cush, 1999), and they have included social sciences (Jackson, 1997) and philosophy (Hella and Wright 2009).

The study of how argumentation studies have been informed by foundational perspectives is important in setting the scene for potential reciprocal interdisciplinary investigations of argumentation in contrast of science and religious education. Both science and religious education have been informed by discussions about cognitive and metacognitive processes and situated cognition perspectives (Brown \& Campione 1990). Understanding the development of reasoning through argumentation has been a longstanding agenda in developmental psychology (Kuhn \& Crowell 2011). From a broad 
educational perspective, the development of communicative competences and particularly critical thinking by means of argumentation is based on assumptions on communicative action and the socio-cultural perspectives. For example, according to the communicative action framework of Habermas (1981), language and communicative competencies play a central role in communicative action. Kelly (2005) notes that in Habermas' framework, individual shifts to a social epistemic subject whilst reason is centred on communicative action and norms for argument are shared. Martin and Hand (2009) report that teachers realign communicative practices in elementary science classrooms by promoting argument. Shifting questioning pattern produces more active student voice, and as student voice increases, elements of science argumentation are practiced (Martin and Hand, 2009, p. 35).

Recent curriculum policies resonate with research in science and religious education in acknowledging the significance of argumentation as a strategy in teaching and learning. In the context of science education, international curriculum standards documents have been advocating the incorporation of argumentation in science teaching and learning. Within Europe, the distinctive feature of argumentation is that it is framed in the development of the scientific competence. Jiménez-Aleixandre and FedericoAgraso (2009) illustrate this point through a discussion of the European Union recommendation of eight key competences (European Union 2006). In other parts of the world, for instance in the USA, the recent development of the Next Generation Science Education Standards (Achieve Lead States 2013) following on from the National Research Council's recommendations (National Research Council 2012) is testimony to the articulation of argumentation as a significant component of scientific practices.

Similarly, argumentation has been advocated as a learning outcome in the context of religious education in curriculum policies from around the world. Although there is no single curriculum for RE in England, for example, there are legally determined local syllabi 
and curricula (Chan et al., 2020). Several national policy documents have been influential although they not statutory (e.g. Qualifications and Curriculum Authority 2004; Department for Children, Schools and Families, 2010). In Scotland, Curriculum for Excellence introduced in 2004 included Religious and Moral Education, and it argued for interdisciplinary learning as an outcome of education. This initiative was consistent with the statuary requirement on the teaching of religion (Hartsborn, 2008).

The review so far illustrates how research trends in research in science and RE have situated argumentation in recent years. Investigating the particular patterns of reference to argumentation in separate lines of work in science education and RE research is beyond the scope of this paper. Rather, by referring to some trends, we have situated the background of our work in the broader educational research literature to provide some context. Likewise, the reference to the foundational disciplines and how they help inform what is meant by argumentation illustrates the diversity of perspectives in each research field, let alone across science and RE. Furthermore, the curriculum and learning contexts of argumentation in science education and RE highlight the complexity issues that underpin each subject and its learning. However, collectively the review also illustrates the necessity to engage in a fairly nuanced manner about how argumentation plays out in teachers' thinking as opposed to a generic take on the science-religion debate.

Yet despite vast amount of research as well as rhetoric in international educational policies, there is still limited understanding of how science and RE teachers consider their subject in comparison. Although there is some research on how science and RE teachers collaborate (e.g. Hall et al, 2014), there are no accounts of such collaboration in the particular context of argumentation. This is fairly surprising given that professional development opportunities for science teachers to develop skills to support students' higher order thinking skills such as argumentation, particularly in the context of complex 
problems, are also underpinned by religious and ethical dimensions (e.g. Simon et al., 2006; Zohar, 2007). In terms of science education, argumentation has centred very heavily on science and socio-scientific issues, the latter mainly concentrating on generic ethical and moral dilemmas without explicit reference to religion as such. For example, ZembalSaul et al. (2002) explored pre-service science teachers' knowledge of argumentation strategies. The researchers stated that the arguments generated by in the study were inadequate in terms of their complexity, and sometimes they did not consider alternative causes.

The purpose of the empirical study reported in the rest of this paper, then, was to investigate how science and RE teachers view argumentation in both their own subject and the other subject. The underlying assumption in the paper is that cross-curricular coherence is important when specific school subjects are advocating similar learning outcomes. In other words, if both science and religious education syllabi are inclusive of argumentation, then students will be introduced to this theme by teachers of different subjects. The extent to which teachers view argumentation, its definition and relation to other school subjects, is important to understand particularly in light of teachers' professional development.

\section{Materials and Methods}

An empirical study was conducted using the responses from 16 science and $17 \mathrm{RE}$ teachers to a survey designed to investigate views and perceptions of various facets of argumentation. The study is part of a 3-year ongoing funded research project based in England (Erduran et al., 2019; Erduran, 2020). The broad goals of the project include understanding how argumentation works in science and religion, and how best to develop teachers' skills for cross-subject considerations including the similarities and the differences between arguments in science and religion. Participants' teaching experiences ranged from one year to 30 years (median 11 years). 23 teachers taught in state schools and 
10 taught in independent schools. 13 teachers taught in schools with a listed 'religious character' (4 Church of England, 5 Catholic, 2 Anglican, and 2 other Christian).

The study is guided by the following research questions:

- What is the nature of science and RE teachers' views of argumentation in their subject and the other subject?

- How do science and RE teachers' views of argumentation compare?

Prior to beginning professional development workshops, recruited teachers were asked to complete a survey, titled the 'Teacher Argumentation Beliefs Inventory' (TABI), to capture their initial views about a wide array of elements of argumentation in both subjects and their use of pedagogical strategies to support argumentation in their classrooms (Erduran et al., in review). This instrument consisted of 73 items in total; 3 demographic questions, 25 open and closed questions about understanding of argumentation and the pedagogy of argumentation, and 45 Likert scale responses in agreement to posed statements about argumentation. A link to the online version of the questionnaire was sent to the participants via email and were completed individually. The research design and data collection procedure for the project was reviewed and approved by the research ethics committee of the authors' affiliation, and the study was carried out following the approved procedure.

This paper reports both quantitative and qualitative data from 6 questions which were specifically targeting the respondent's views of the comparison of argumentation between the two subjects. One question specifically asked for their view about how arguments in science and religion compare, ranging from very different to very similar, with an open response to explain. Two questions ask about the extent that the teachers believe either subject has scope for eliciting students' opinions. Two more questions ask 
teachers to respond to statements about the use of evidence or substantiation in science and RE respectively.

Closed questions are reported with frequency counts and open responses were analysed using a standard thematic analysis (Braun and Clarke 2006). These themes were generated by focusing on the semantic meanings of the responses (Braun and Clarke 2006, p. 83). For example, the quotes 'Occasionally, they address the same question, but in a different way' (T19, RE) and 'they seek to answer different questions about human experience and significance' (T21, Science) would be coded to the broad theme 'Different or Similar Questions' which reflects the semantic meaning of the remarks made by the teachers. Initial thematic analysis of open responses was conducted by one author. Interpretations were crossed checked by another author using Intercoder Agreement (ICA) processes (Guest et al. 2012). ICA was greater than 95\% for each theme. Disagreements were resolved through revision of the descriptions of the theme.

\section{Results}

Table 1 shows that it was quite unusual for teachers to view argumentation in science and religion as very different. In fact, the vast majority of respondents took a more balanced view, that there are both similarities and differences between the arguments in science and religion. Other teachers felt that though there are differences and similarities, these are imbalanced such that there are either more similarities than differences or more differences than similarities between them. The latter was the more popular opinion, particularly for science teachers. However, it is clear that for this group of teachers, there was at least some sense of similarity or overlap between the arguments of either subject. The findings indicate that science teachers may not see science and religion as necessarily in conflict, as some sources in the literature would suggest (e.g. Mansour 2015). The questions posed to the teachers were intentionally neutral in content and did not refer to any potential conflict 
between science and religion in a broad sense because such a broad and generic take on science versus religion was not the aim of the study. Rather, when comparing science and religion, teachers were asked fairly specific questions about argumentation such as "how do you view the comparison between arguments in science and arguments in religion?"

[Table 1 near here]

Other closed-response questions are fruitful in understanding the positions of these science and RE teachers as they think about the differences and similarities in their subjects. Responses to the first statement (leftmost) in Figure 1 shows that the majority of both science and RE teachers agreed that arguments in science rely more on evidence than arguments in RE. Of course, what is meant by 'evidence' is important here, and teachers views on this become clearer in the qualitative remarks reported later.

[Figure 1 near here]

To the extent that argumentation can be considered to elicit students' opinions, the respondents considered whether the subjects of science and RE provided opportunities for doing so. Responses to the second statement in Figure 1 shows that most science teachers agree that there is scope in science education for students to express their own opinions. More RE teachers were unsure about this as a possibility. Most RE teachers neither agreed nor disagreed, possibly suggesting unfamiliarity about what happens in science classrooms in order to make a judgement. The third statement in Figure 1 probed the same point but for the subject of RE. Most teachers, of both science and RE, agree that RE provides scope for eliciting students' opinions. That science teachers do not appear to register the same unease in responding to this question as the RE teachers did of the previous question may be indicative of a common perception that RE is a subject primarily concerned with expressing and discussing views. The fourth statement targets teachers' beliefs about the substantiation necessary for arguments in the RE context. The responses show that some 
science teachers were unsure whether or not students must go beyond merely expressing or discussing their opinions in RE. Conversely, RE teachers were unanimous in considering it insufficient for a student to present an unsubstantiated claim.

Evidently, there are some differences in how the science and RE teachers consider the nature of argumentation in their own and the 'other' subject and to what extent each subject allows students to express their opinions. It is thus helpful to examine teachers' qualitative explanations for their positions. Teachers were asked to provide an explanation, in a free-text box, for the position they selected to the original question reported in Table 1. These are explored below.

Table 6 displays the themes generated from the analysis of teachers' free-text explanations, along with a frequency count of codes for these themes and a description of each. It is clear that two ideas dominated the responses, the notion of evidence and the structures or processes of argumentation. Other themes included the place of values in argumentation, the kind of questions that science and RE deal with, the nature of argument and the use of scientific method.

[Table 2 near here].

\section{Difference in Evidence}

The most dominant feature in these teachers' explanations of their position on the difference or similarity of arguments in science and religion was that of 'evidence'. Comments about evidence ranged from simple perceived dichotomies ('one is evidence based, one is belief based' T34, Science) to assertions that there might be both overlapping and unique forms of evidence accepted in the two subjects ('There are empirical arguments in religion [hence similarity]. But there is also a reliance on faith in religion [hence dissimilarity]' T22, RE). Figure 1 indicates that all RE teachers felt unsubstantiated claims were unacceptable in their subject, but their comments indicate that a wider array of forms 
of substantiation, or 'evidence', would be accepted in their subject: 'Arguments in science seem to be strictly based on empirical evidence, whereas arguments in philosophy and theology go beyond this' (T27, RE). Some science teachers, too, recognised that evidence utilised in RE arguments could be 'based on interpretation of scripture or rhetoric' (T06, Science) and also noted differences in the permissibility of differing forms of substantiation:

\footnotetext{
... it is more academically permissible to hold a belief and to write from the perspective of that belief being potentially true as a theologian... Science has a more rigid set of rules (T21, Science)
}

In addition to the nature of accepted evidence, some teachers also pointed to the differences in scrutiny to which that evidence can be subjected. For example, one RE teacher describes the evidence for scientific arguments as 'generally testable' while arguments in RE 'although can be evidenced, [are] less testable' and that 'reasoning and logic are separate from the testability of evidence' (T07, RE). Viewed from the research on teaching argumentation, this example shows that some teachers, even before any professional development interventions, already have a rough idea of key elements of argumentation such as evidence and reasoning (Toulmin, 1958) and the distinction between these concepts.

\section{Similar Structures and Processes}

In making comparisons, many teachers referred to the idea that the fundamental structures or processes of argumentation might be a point of similarity between the subjects. For example, one teacher stated that 'arguments in both disciplines involve logically considering an idea and putting forward an argument, based on the evidence available' (T03, Science) and another stated 'I think there are strong structural similarities between 
the language used to develop and support arguments' (T11, RE). So, even if the forms of evidence differ, teachers perceived that arguments could be similar in their processes such as 'the use of inference in drawing conclusions, from scientific data and e.g. scriptural interpretation' (T32, Science).

That teachers of both subjects see similarities in terms of the structure of arguments in their respective subjects provides indication that there may be scope for productive interdisciplinary collaboration and, as they see it, for teaching students transferable skills ( 'The skill of using evidence is, however, transferable' T36, RE; 'The method of argument I'm sure is the same. The viewpoints may differ' T31, Science). These responses stand in line with the recent emphasis on the domain-general aspects of argumentation that are fundamental across disciplines (e.g., Goldman, Ko, Greenleaf and Brown, 2018; Hetmanek, Engelmann, Opitz and Fischer, 2018), which can be an effective starting point for cross-subject collaborations.

\section{Place of Values}

While only 4 teachers invoked the idea of values in their responses, it is notable that there were two alternative perspectives on the role played by values in the comparison of arguments in science and RE. On one hand, science was viewed as the domain of fact and RE the domain of values, with only minor overlap on areas of ethical use of science: 'Science arguments are usually based on facts, evidence, data, which is very different from RE. The topics only overlap where ethical issues are concerned' (T10, Science). In this sense, the place of values is more of a distinguishing feature between the subjects than a unifying one. On the other hand, values were also described as pervasive throughout science: 'Once an argument starts in science it requires values' (T30, RE). This perspective would suggest that values are, in fact, one of the unifying features of arguments between the two subjects. Whether a unifying feature or not, in both perspectives, teachers were 
recognising that values have at least some place in arguments in science as well as in RE, which aligns with what is emphasised by education researchers (Kolstø \& Ratcliffe, 2007; Zeidler \& Sadler, 2007). Other teachers advanced the idea that it may be the relative weight of such values in science versus RE arguments that is the important difference:

Differences are more likely to be seen when questioning the significance of beliefs for individuals and then in how might these beliefs be implemented within ethical decision making (T11, RE)

Differences include the value placed on experiences and conclusions and how they are applied. Examples would include in the areas of medical ethics. (T32, Science)

\section{Difference about Questions and Nature of Argument}

The idea that science and RE might be concerned with different sorts of questions was highlighted by both science and RE teachers: 'They seek to answer different questions about human experience and significance' (T21, Science); 'I think the subjects attempt to address different questions' (T19, RE). Where these subjects might be concerned with the same question, this teacher suggested that the subjects would take different approaches to generating an answer: 'Occasionally, they address the same question, but in a different way. I think RE is concerned with why, and science with how' (T19, RE). Another RE teacher acknowledged this distinction as common, but suggested that there are some big questions for which the two disciplines are fundamentally addressing truth claims:

I understand the standard 'science asks how questions and religions asks why questions', point but I think, particularly with questions about origins, both religion and science regard such as first order questions. Therefore, for both disciplines they are equally important. Also, both religion and science (at least amongst some more 'popular' and 'public' scientists) make truth claims. (T33, RE).

Supporting this idea that there are some areas where both science and RE would be equally 
concerned by the same questions, other RE teachers pointed out that this discussion of similarity and difference 'would really depend on the nature of religious argument' (T15, $\mathrm{RE})$. That is to say that RE teachers recognised that there are different sorts of arguments that are encountered by students in RE and that some of these are more similar to science than others.

The distinction between empirical arguments and reliance on faith was again highlighted as teachers invoked the idea of the scientific method as a route to answering questions. One RE teacher stated that 'religious studies cannot always use a scientific/empirical method' (T24, RE). The inclusion of the word 'always' here suggests a perception that there are at least some questions in RE for which the scientific method or empirical approach could be utilised. When a similar point was articulated from a science teacher's perspective, it was stated without explicit reference to RE but with some qualifying language that suggests a more tentative stance towards the impartiality of the scientific approach: 'The scientific method takes a particular approach to ideas which seeks/claims to be less subjective' (T23, Science). Here, there is no definitive indication about whether or not RE might utilise the scientific method to seek answers to questions. However, the words 'seeks/claims to be' may be suggestive of a perception that the scientific method cannot be entirely devoid of subjectivity. This sort of approach to comparing the two subjects appears to be one of 'degrees' of similarity or difference, rather than outright distinctions between the two.

\section{Doubt}

The final point of comparison, raised by two RE teachers, was about the role of doubt in each subject. Again, there were two different perspectives asserted. The first perspective appears to suggest that knowledge in science is not in doubt ('within science I assume there are less students and teachers doubting the results of experiments' T02, RE) while the 
second appears to propose the opposite ('there may be no room for doubt in religion, whereas in science there is' T22, RE). Interpreted differently, these might actually be considered to be two aspects of the same perspective. Together, these suggest a possibility that when claims are of an empirical nature, the evidence proposed in science would be less in doubt than the evidence proposed in RE, but when claims are rooted in faith, a scientific perspective would remain doubtful while faith from a religious perspective would be characterised by the absence of doubt.

\section{Discussion}

The primary purpose of this paper was to investigate how science and RE teachers view the nature of argumentation in their own subject and the other subject. The findings illustrate how teachers describe both distinguishing features (such as the forms of evidence acceptable for substantiating a claim) and similarities (such as the structures and processes of argument construction). It is important to acknowledge and recognise that this study does not aim for generalisable findings about how RE and science teachers think about argumentation. Given the relatively small sample size of the participants as well as the focus on qualitative responses, the intention was rather to gain an in-depth understanding of how teachers view argumentation in school subjects. The findings demonstrated that there is a diversity of quite nuanced opinions even amongst this small sample of teachers.

It might be expected that teachers who are voluntarily engaging in collaborative professional development between science and RE would see particular synergies between their subject and the other subject. However, even if these views are a subset of the wider teaching populations' views, the existence of their views in the context of the study in which they were elicited (professional development of science and RE teachers on argumentation) is of interest. These views help us to understand how science and RE teachers may perceive their own subject and the 'other' subject when asked to consider the 
teaching and learning of argumentation as a component of a broad school curriculum. These teachers' views facilitate us to unearth potential opportunities and challenges for cross-curricular and interdisciplinary teaching of argumentation.

Key elements of their perspectives and what professional development may need to address include: what evidence is acceptable; what types of questions, topics or claims the arguments are addressing; what are the place of values and doubt; and how might structures of argument appear similar yet have differences? One way to look at the points raised by teachers is that there are tensions here that need resolution. Alternatively, the findings might be considered as nuanced and as matters of 'degree'. For example, science is perceived to have more empirical arguments and less in doubt of empirical evidence offered, or RE is more concerned with arguments where values are central. None of these are perceived as absolutes but matters of more and less. Though it is tempting in interdisciplinary work to seek what is distinctive about either discipline, the reality may be a little less clearly defined. The results underscore the importance of teaching about argumentation across these subject boundaries so students would be able to more astutely discern the differences between the arguments where they might otherwise be easily confused.

Overall, the paper contributes to research on teachers' views of argumentation (e.g. Zohar \& Schwartzer, 2005) and provides insights into how teachers' reflections on argumentation can potentially play out in their appropriation of relatively unfamiliar pedagogical strategies in cross-curricular contexts. More broadly, the research contributes to understanding of how teachers' views influence their knowledge (Cochran-Smith \& Lytle, 1999). The indications from this research are that science teachers and RE teachers do not necessarily view their subjects as in conflict as some studies have previously suggested (e.g. Mansour 2015). While most teachers can draw distinctions between the 
arguments generated in either subject, they are also able to highlight areas of convergence and common purpose such that learning from one another would be potentially constructive activity particularly in relation to establishing coherence across the whole school curriculum. Research on teachers' views of argumentation can help us understand how to engage science and RE teachers in interdisciplinary collaborations and professional development. Ultimately research informed by teachers' views will help with the design of effective teaching and learning approaches which infuse argumentation in lessons such that students are best equipped with the skills to deal with a range of issues faced in their everyday lives.

\section{Acknowledgements}

[Acknowledgement to funder be inserted after peer review, see title page].

\section{References}

Basel, N., Harms, U, \& Prechtl, H. (2013). Analysis of students' arguments on evolutionary theory. Journal of Biological Education. 47 (4),192-199.

Braun, V., \& Clarke, V. (2006). Using thematic analysis in psychology. Qualitative Research in Psychology, 3(2), 77-101.

Brown, A. L. \& Campione, J. C. (1990). Communities of learning and thinking, or a context by any other name. In D. Kuhn (Ed.), Developmental perspectives on teaching and learning thinking skills. Contribution to Human Development, 21, 108-126.

Chan, J., Fancourt, N., \& Guilfoyle, L. (in press). Argumentation in religious education in England: An analysis of locally agreed syllabuses. British Journal of Religious Education. DOI:10.1080/01416200.2020.1734916

Cochran-Smith, M., \& Lytle, S. L. (1999). Relationships of Knowledge and Practice: Teacher Learning in Communities. Review of Research in Education, 24, 249-305.

Council for the Curriculum Examinations and Assessment (2009). Religious Education, Thinking Skills and Personal Capabilities Progression Maps at Key Stage 3. Belfast, Northern Ireland, UK.

Cush, Denise. 1999. "The Relationships between Religious Studies, Religious Education and Theology: Big Brother, Little Sister and the Clerical Uncle?" British Journal of Religious Education 21 (3):137-146.

Department for Children, Schools, and Families. 2010. Religious education in English schools: $\quad$ Non-statutory guidance 2010. DSCF https://assets.publishing.service.gov.uk/government/uploads/system/upload s/attachment_data/file/190260/DCSF-00114-2010.pdf 
Duschl, R. A., \& Osborne, J. (2002). Supporting and promoting argumentation discourse in science education. Studies in Science Education, 38, 39-72.

Erduran, S. (2019). Argumentation in chemistry education: Research, policy and practice. London: Royal Society of Chemistry.

Erduran, S. (2020). Argumentation in science and religion: match and/or mismatch when applied in teaching and learning? Journal of Education for Teaching, 46(1), 129131.

Erduran, S., \& Garcia-Mila, M. (2015). Epistemic practices and thinking in science: Fostering teachers' development in scientific argumentation. In R. Wegerif, L. Li, \& J. Kaufman (Eds.), The Routledge International Handbook of Research on Teaching Thinking (pp. 388-401). Abingdon: Taylor and Francis.

Erduran, S., Guilfoyle, L., Park, W., Chan, J., \& Fancourt, N. (2019). Argumentation and Interdisciplinarity: Reflections from the Oxford Argumentation in Religion and Science Project. Disciplinary and Interdisciplinary Science Education Research, $1(1)$.

Erduran, S., \& Jiménez-Aleixandre, M. P. (Eds.). (2007). Argumentation in science education: Perspectives from classroom-based research Dordrecht: Springer.

Goldman, S. R., Ko, M.-L. M., Greenleaf, C., \& Brown, W. (2018). Domain-specificity in the practices of explanation, modelling, and argument in the sciences. In F. Fischer, C. A. Chinn, K. Engelmann, \& J. Osborne (Eds.), Scientific reasoning and argumentation: The roles of domain-specific and domain-general knowledge (pp. 121-141). London: Routledge.

Guest, G., MacQueen, K. M., \& Namey, E. E. (2012). Applied Thematic Analysis. Thousand Oaks, CA: SAGE.

Habermas, J. (1981). The Theory of Communicative Action. Boston: Beacon Press.

Hall, S., McKinney, S., Lowden, K., Smith, M., \& Beaumont, P. (2014). Collaboration between Science and Religious Education teachers in Scottish Secondary schools. Journal of Beliefs \& Values, 35(1).

Hartsborn, B. (2008). Religious and moral education. In Scottish Education Third Edition beyond Devolution, edited by T. G. K Bryce and W. M. Humes, 375-382. Edinburgh: Edinburgh University Press.

Hella, Elina, and Andrew Wright. 2009. "Learning 'about' and 'from' religion: phenomenography, the Variation Theory of Learning and religious education in Finland and the UK." British Journal of Religious Education 31 (1):53-64.

Hetmanek, A., Engelmann, K., Opitz, A., \& Fischer, F. (2018). Beyond intelligence and domain knowledge: Scientific reasoning and argumentation as a set of crossdomain skills. In F. Fischer, C. A. Chinn, K. Engelmann, \& J. Osborne (Eds.), Scientific reasoning and argumentation: The roles of domain-specific and domaingeneral knowledge (pp. 203-226). London: Routledge.

Jackson, Robert. 1997. Religious education: an interpretive approach. London: Hodder \& Stoughton.

Jiménez-Aleixandre, MP, \& Federico-Agraso, M. (2009). Justification and persuasion about cloning: arguments in Hwang's paper and journalistic reported versions. Research in Science Education, 39(3), 331-347.

Kelly, G. J. (2005). Inquiry, activity, and epistemic practice. Proceedings of the Inquiry Conference on Developing a Consensus Research Agenda, Rutgers University.

Kitcher, P. (1988). The child as parent of the scientist. Mind and Language, 3(3), 215-228.

Kolstø, S. D., \& Ratcliffe, M. (2007). Social aspects of argumentation. In S. Erduran \& Jiménez-Aleixandre, M. P. (Eds.), Argumentation in science education: Perspectives from classroom-based research (pp. 117-136). Dordrecht: Springer. 
Kuhn, D, \& Crowell, A. (2011). Dialogic argumentation as a vehicle for developing young adolescents' thinking. Psychological Science, 22(4), 545-552.

Lee, M-H, Wu, Y, Tien, T, \& Chin-Chung, A. (2009). Research trends in science education from 2003 to 2007: a content analysis of publications in selected journals. International Journal of Science Education, 31(15), 1999-2020.

Lin, TC, Lin, TJ, \& Tsai, CC. (2014). Research Trends in Science Education from 2008 to 2012: a systematic content analysis of publications in selected journals. International Journal of Science Education, 36(8), 1346-1372.

Mansour, N. (2015) Science Teachers' Views and Stereotypes of Religion, Scientists and Scientific Research: A call for scientist-science teacher partnerships to promote inquiry-based learning, International Journal of Science Education, 37(11), 17671794, DOI: $10.1080 / 09500693.2015 .1049575$

Martin, A. M., \& Hand, B. (2009). Factors affecting the implementation of argument in the elementary science classroom: a longitudinal case study. Research in Science Education, 39(1), 17-38.

NGSS Lead States. (2013). Next generation science standards. Retrieved from http://www. nextgenscience.org/

Niemela, M. A., \& Tirri, K. (2018). Teachers' knowledge of curriculum integration: a current challenge for Finnish subject teachers

Pera, M. (1994). The discourses of science. Chicago: University of Chicago Press.

Qualifications and Curriculum Authority. 2004. Religious Education: The Non-statutory National Framework. London: QCA.

Reiss, M. J. (2008). Should science educators deal with the science/religion issue? Studies in Science Education, 44(2), 157-186.

Sadler, T.D. (2006). Promoting discourse and argumentation in science teacher education. Journal of Science Teacher Education, 17: 323.

Sadler, TD, \& Zeidler, DL. (2005). Patterns of informal reasoning in the context of socioscientific decision making. Journal of Research in Science Teaching, 42(1), $112-138$.

Siegel, H. (1991) The rationality of science, critical thinking, and science education. In M.R. Matthews (Ed.), History, philosophy and science teaching: Selected readings (pp. 45-62). Toronto: OISE Press.

Schwartz, B. B., \& Baker, M. J. (2017). Dialogue, argumentation and education: history, theory and practice. Cambridge: Cambridge University Press.

Stenmark, M. (2004). How to Relate Science and Religion: A Multidimensional Model, Grand Rapids, MI: Eerdmans.

Thagard, P., \& Findlay, S. (2010). Getting to Darwin: Obstacles to accepting evolution by natural selection. Science \& Education, 19(6-8), 625-636.

Toulmin, S. (1958). The uses of argument. Cambridge: Cambridge University Press.

Weiß, T. (2016). Fachspezifische und fachübergreifende Argumentationen am Beispiel von Schöpfung und Evolution. [Specialist and multidisciplinary Arguments Using the Example of Creation and Evolution]. Gottingen: V\&A.

Zeidler, D.L. \& Nichols, B.H. (2009). Socio-scientific issues: Theory and practice. Journal of Elementary Science Education, 21: 49.

Zeidler, D. L., \& Sadler, T. D. (2007). The role of moral reasoning in argumentation: Conscience, character, and care. In S. Erduran \& Jiménez-Aleixandre, M. P. (Eds.), Argumentation in science education: Perspectives from classroom-based research (pp. 201-216). Dordrecht: Springer. 
Zembal-Saul, C., Munford, D., Crawford, B., Friedrichsen, P., \& Land, S. (2002). Scaffolding Preservice Science Teachers' Evidence-Based Arguments During an Investigation of Natural Selection. Research in Science Education, 32(4), 437-463.

Zohar, A., \& Schwartzer, N. (2005). Assessing teachers' pedagogical knowledge regarding issues pertaining to instruction of higher order thinking. International Journal of Science Education, 27, 1595-1620.

Zohar, A. (2007). Science Teacher Education and Professional Development in Argumentation. In S. Erduran \& M. P. Jiménez Aleixandre (Eds.), Argumentation in Science Education. Dordrecht: Springer. 